Atmos. Chem. Phys. Discuss., 10, 1595-1629, 2010 www.atmos-chem-phys-discuss.net/10/1595/2010/ (C) Author(s) 2010. This work is distributed under the Creative Commons Attribution 3.0 License. and Physics (ACP). Please refer to the corresponding final paper in ACP if available.

\title{
Cluster analysis of midlatitude oceanic cloud regimes - Part 2: Temperature sensitivity of cloud properties
}

\section{N. D. Gordon ${ }^{1, *}$ and J. R. Norris ${ }^{1}$}

${ }^{1}$ Scripps Institution of Oceanography, University of California, San Diego, La Jolla, CA, USA *now at: School of Earth and Environment, University of Leeds, Leeds, UK

Received: 17 November 2009 - Accepted: 28 December 2009 - Published: 20 January 2010 Correspondence to: N. D. Gordon (n.gordon@leeds.ac.uk)

Published by Copernicus Publications on behalf of the European Geosciences Union.
ACPD

10, 1595-1629, 2010

Cluster analysis of midlatitude oceanic cloud regimes

N. D. Gordon and J. R. Norris

Title Page

Abstract Introduction

Conclusions References

Tables Figures

14 $\rightarrow$

4

Back

Close

Full Screen / Esc

Printer-friendly Version

Interactive Discussion 


\section{Abstract}

Clouds have a large impact on Earth's radiation budget by reflecting incoming solar radiation and trapping longwave radiation emitted from the surface. The present balance could change as the atmosphere warms from increasing anthropogenic greenhouse 5 gases, thus altering the net radiation flux and mitigating or exacerbating the initial temperature increase. To ascertain the sign and magnitude of cloud-climate feedback, we must better understand the way in which clouds interact with their environment and how temperature modifies cloud and radiative properties. Since global climate models do not consistently and correctly simulate clouds, we undertake an observational analysis of how midlatitude oceanic clouds change with temperature when dynamical processes are held constant (i.e., partial derivative with respect to temperature). For each of the seven cloud regimes identified through $k$-means clustering of daily satellite data in the companion study, we examine the difference in cloud and radiative properties between warm and cold subsets. To avoid misinterpreting a cloud response to large-scale dynamical forcing as a cloud response to temperature, we require horizontal and vertical temperature advection in the warm and cold subsets to have near-median values in three layers of the troposphere. Across all of the seven clusters, we find that cloud fraction is smaller and cloud optical thickness is mostly larger for the warm subset. Cloud top pressure is higher for the three low-level cloud regimes and lower for the cirrus regime. The net upwelling radiation flux at the top of the atmosphere is larger for the warm subset in every cluster except cirrus, and larger when averaged over all clusters. This implies that the direct response of midlatitude oceanic clouds to increasing temperature acts as a negative feedback on the climate system. Note that the cloud response to atmospheric dynamical changes produced by global warming, which we do not consider in this study, may differ, and the total cloud feedback may be positive.

Cluster analysis of midlatitude oceanic cloud regimes

N. D. Gordon and J. R. Norris

Title Page

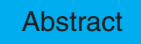

Introduction

Conclusions

Tables References Figures

14

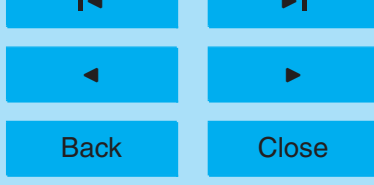

Full Screen / Esc

Printer-friendly Version

Interactive Discussion 


\section{Introduction}

In order to fully understand how increased carbon dioxide and other greenhouse gases impact the Earth's climate system, we must know how clouds respond to anthropogenic warming. Clouds play an integral role in the climate system by reflecting solar radiation 5 back to space and restricting the emission of terrestrial radiation to space. The balance between cooling and warming by clouds is an important control on the temperature of Earth's surface. Clouds over midlatitude oceans reflect as much as $200 \mathrm{~W} \mathrm{~m}^{-2}$ more shortwave radiation than clear sky (Weaver and Ramanathan, 1997), while the total direct radiative forcing of a doubling of atmospheric $\mathrm{CO}_{2}$ is about $3 \mathrm{~W} \mathrm{~m}^{-2}$. Since clouds have such a large influence on Earth's energy budget, it is important to understand how they and their impacts on radiative transfer might respond to an initial warming from increased $\mathrm{CO}_{2}$; this is known as the cloud-climate feedback.

Global climate models can provide insight into the mechanisms of our climate system and how it might respond to external perturbations, such as warming from increased greenhouse gases. At present, however, there is no agreement between different models on the magnitude, and even the sign, of the cloud-climate feedback. Through use of the radiative kernel method, Soden and Held (2006) found that the sign of the cloud feedback was uniformly positive for 14 different coupled atmosphere-ocean models even though changes in cloud radiative forcing with global warming ranged from weakly negative to strongly positive (Soden et al., 2008). Several recent studies have investigated the sensitivity of cloud properties to temperature with global climate models (Ringer et al., 2006; Webb et al., 2006; Williams and Tselioudis, 2007; etc). The latter paper examined differences between simulated cloud properties in control runs and $2 \times \mathrm{CO}_{2}$ experiments through the use of a clustering algorithm. Previous work has demonstrated that clustering is an effective method for separating satellite data into different cloud regimes, each accompanied by distinct dynamics and thermodynamics (Jakob and Tselioudis, 2003; Gordon et al., 2005; Jakob et al., 2005).
Cluster analysis of midlatitude oceanic cloud regimes

N. D. Gordon and J. R. Norris

Title Page

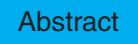

Introduction

Conclusions

Tables

References

Figures

14

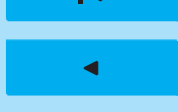

$>1$

Back

Close

Full Screen / Esc

Printer-friendly Version

Interactive Discussion 
The cloud feedback produced by models can be better constrained by examining how observed cloud properties are related to temperature and other meteorological processes. Building on the classification system described in Part 1 of this study (Gordon and Norris, 2010), the present analysis diagnoses the sensitivity of cloud properties 5 particularly their ability to affect the flux of radiation in the atmosphere - to changes in atmospheric temperature. We use a method similar to that proposed by Bony et al. (2004) to distinguish the cloud response to temperature from the cloud response to dynamics. Since dynamical processes can influence both temperature and clouds and thus act as a confounding factor, we investigate how cloud properties vary with temper10 ature within a narrow range of dynamical parameters. This approach is aided by first classifying the data into cloud regimes, each with its own particular meteorology. Unlike other studies that examined sensitivity of cloud properties to temperature change in the tropics (Cess et al., 1992; Bony et al., 1997; Tian and Ramanathan, 2002), we focus on midlatitude oceans where clouds have the largest impact on the net radiation 15 budget (Weaver and Ramanathan, 1996).

In the present study, we apply a $k$-means clustering algorithm to daily International Satellite Cloud Climatology Project (ISCCP) data in $280 \mathrm{~km}$ grid boxes over $\mathrm{NH}$ and SH midlatitude oceans. Part 1 of this study, Gordon and Norris (2010), identified seven cloud clusters over midlatitude oceans, along with their corresponding vertical profiles of temperature, humidity, vertical velocity, horizontal temperature advection, and horizontal moisture advection. This allowed us to group cloud scenes with similar largescale dynamical conditions, and in Part 2 we divide each cluster into relatively warm and cold subsets. In order to remove the impact of joint dynamical forcing on temperature and cloudiness, we restrict warm and cold subsets to have near-median values of horizontal and vertical temperature advection and near-median values of lapse rate in the lower troposphere and tropopause region. The difference between cold and warm subsets provides information on how large-scale cloud and radiative properties are affected by increasing temperature directly rather than through changes in atmospheric circulation associated with global warming. These results will give insight into cloud

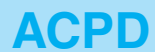

$10,1595-1629,2010$

Cluster analysis of midlatitude oceanic cloud regimes

N. D. Gordon and J. R. Norris

Title Page
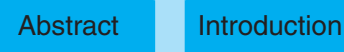

Conclusions

Tables References Figures

14

4

Back

Full Screen / Esc

Printer-friendly Version

Interactive Discussion 


\section{Data sources}

The source of cloud observations for this investigation was the three-hourly ISCCP D1 equal-area $(280 \mathrm{~km} \times 280 \mathrm{~km})$ data set, originally processed from radiances primar5 ily measured by geostationary weather satellites, with lesser contribution from polarorbiting satellites (Rossow et al., 1996; Rossow and Schiffer, 1999). The ISCCP data consist of cloud fractions within a gridbox in three intervals of cloud-top pressure (CTP) and cloud optical thickness $(\tau)$, giving us nine CTP- $\tau$ categories. Because cloud optical thickness is based on visible retrievals, valid data only exist for daytime hours, and we 10 furthermore restricted our analysis to the one time point per day for each satellite gridbox with the smallest solar zenith angle (closest to local noon). This restriction avoided biases associated with more valid data points from regions near the equator and from points in the summer hemisphere, where there are a greater number of daylight hours.

Additional quality control included removal of all grid box values with any sea ice, as 15 reported by the satellite, or any points with anomalously high clear-sky albedo $\left(\alpha_{\text {clear }}\right)$. The normal range of $\alpha_{\text {clear }}$ was determined for bins of solar zenith angle (SZA) by calculating the difference between the 1 st percentile and the median value. For each SZA bin, all data for which $\alpha_{\text {clear }}$ values were greater than the sum of the median and the difference between the median and the 1st percentile value were excluded. 20 This assumes that valid $\alpha_{\text {clear }}$ varies uniformly above and below the median. We also excluded data for which satellite skin temperature $\left(T_{\text {skin }}\right)$ was less than $271 \mathrm{~K}$, more than $4 \mathrm{~K}$ colder than NCEP reanalysis SST, or more than $8 \mathrm{~K}$ warmer than reanalysis SST. As noted by Tsuang et al. (2008) (Fig. 3 from Tsuang et al., 2008), $T_{\text {skin }}$ tended to be warmer than NCEP reanalysis SST by about $2 \mathrm{~K}$ for most observations over the midlatitude oceans. All of these restrictions removed less than $1 \%$ of the initial data, but it was necessary to ensure that spurious clear-sky values did not contaminate our analysis of changes in cloud radiative properties.

\section{Cluster analysis of midlatitude oceanic cloud regimes}

N. D. Gordon and J. R. Norris

Title Page
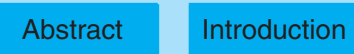

Conclusions

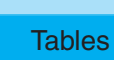

References

Tables

Figures

14

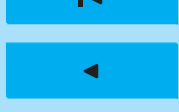

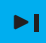

Back

Close

Full Screen / Esc

Printer-friendly Version

Interactive Discussion 
The ISCCP Flux Dataset (Zhang et al., 2004) provided upwelling and downwelling, shortwave (SW) and longwave (LW) radiation fluxes derived from ISCCP cloud properties and related data for clear and cloudy parts of the grid box at the surface. Since our selection of the one satellite observation per day that is closest to local noon would 5 otherwise produce a substantial radiative bias, we divided near-noon upwelling TOA SW fluxes by near-noon insolation to convert them to values of reflectivity. Reflectivity values were multiplied by diurnal mean insolation to convert them back to diurnal mean upwelling SW flux (more details are available in the Appendix of Part 1). This procedure assumes that systematic cloud changes near local noon are characteristic of the entire 10 day. Averaging diurnal mean flux values across different grid boxes and seasons gives more radiative weighting to cloud changes that occur at lower latitudes and during the summer season. While this may be more relevant to the overall impact on climate, in the present study we are more interested in the typical cloud response to increasing temperature. For this reason we gave equal weighting to clouds in all grid boxes and 15 seasons by separately averaging reflectivity values and diurnal mean insolation values before multiplying them together to obtain average diurnal mean upwelling flux. Our results are qualitatively the same irrespective of radiative weighting.

We analyzed cloud and radiation data from nearly the entire record of ISCCP, 21 years (1984-2004), over the domain of all ocean points between $30^{\circ}$ and $50^{\circ}$ in both hemispheres, representing 1444 gridboxes. The total number of daily gridbox cloud observations is almost 10 million, each consisting of a CTP- $\tau$ histogram, which is an array of cloud fraction for nine cloud type categories. This very large data collection enables a comprehensive investigation of the cloud response to temperature when large-scale dynamical conditions are held constant. We chose to examine only ocean 25 points so that surface conditions would be more uniform.

We obtained information about the dynamical and thermodynamical structure of the atmosphere from the National Center for Environmental Prediction (NCEP)/National Center for Atmospheric Research (NCAR) Reanalysis (Kalnay et al., 1996). This data set provided standard meteorological parameters from which we derived horizontal and

Cluster analysis of midlatitude oceanic cloud regimes

N. D. Gordon and J. R. Norris

Title Page

Abstract

Conclusions

Tables

Figures

14

4

Back

Introduction
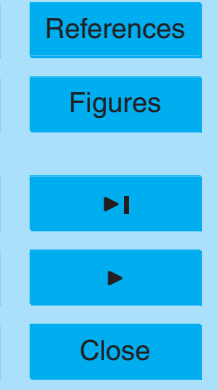

Full Screen / Esc

Printer-friendly Version

Interactive Discussion 
vertical advective tendencies of moisture and temperature using large-scale gradients and atmospheric motions, both of which are important to the formation of clouds. Much of the dynamical forcing that leads to cloud formation is at or above the spatial scale of the satellite gridboxes in the midlatitudes, and vertical motion in the NCEP-NCAR

5 reanalysis is best constrained in the midlatitudes. For each of our 10 million data points, we have cloud properties from ISCCP, radiative flux in the atmosphere derived from these cloud properties, and meteorology and sea-surface temperature from NCEP Reanalysis.

\section{Clustering and temperature restriction}

10 The clustering algorithm used in the present analysis is discussed in detail in the companion study (Part 1). The $k$-means procedure classifies all data elements into a specified number of clusters such that within-cluster variance is minimized (Hartigan, 1975; Jakob and Tselioudis, 2003). The only arbitrary parameter needed is the number of clusters; the character of the individual cluster means is then objectively determined by the data. The clustering process began with random selection of $k$ data elements as initial seeds, each element comprising a nine-type array of cloud fraction in each CTP- $\tau$ category. All other elements in the data set were then assigned to the initial seed to which they were closest in a Euclidean sense. The number of elements in a cluster divided by the total number of elements is the frequency of occurrence of the cluster, and the average of all elements in the cluster is the centroid. These cluster centroids became new seeds to reinitialize the clustering routine, which was repeated until the centroids converged. Clear-sky observations, which are infrequent (occur less than $1 \%$ of the time), and for which all values of the nine-type array are exactly 0 , were excluded from this analysis.

25 We used tropospheric mean temperature rather than SST to act as a proxy temperature change due to anthropogenic global warming because tropospheric temperature has much more variance at daily time scales than SST and best represents the

Cluster analysis of midlatitude oceanic cloud regimes

N. D. Gordon and J. R. Norris

Title Page

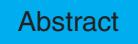

Introduction

Conclusions

Tables

References

Figures

14

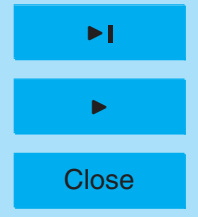

Back

Full Screen / Esc

Printer-friendly Version

Interactive Discussion 
temperature experienced by clouds. In order for a case to be considered relatively warm (or cold), it had to be above (or below) the median of tropospheric mean temperature for each ISCCP gridbox, calendar month, and cluster number. This uniform sampling ensures that no geographical or seasonal biases are introduced. As observed by 5 Norris and lacobellis (2006), temperature advection is a large contributor to local temperature variability. In order to eliminate a possible confounding dynamical influence, we require that all cases be between the 25th and 75th percentile of horizontal and vertical temperature advection. This is conducted independently for three different layers of the atmosphere, which corresponded to the layers of the ISCCP cloud histograms 10 (1000-680 mb, 680-440 mb, and 440-100 mb). Examining warm-cold differences in cloud properties only for conditions of median advection minimizes the possibility of a misinterpreting a cloud-temperature relationship produced by large-scale dynamics for a thermodynamic response. Such confusion could arise because variability in cloud amount, temperature, advection, and the storm track are closely connected over mid15 latitude oceans (Norris, 2000).

Two more meteorological conditions that we restricted were lower-tropospheric static stability (LTS) and the tropopause height. The former has particular influence on lowlevel cloud properties (Klein and Hartmann, 1993; Norris, 1998), while the latter primarily affects the high-cloud clusters. Because advection over the ocean produces 20 a greater change in temperature in the mid-troposphere than near the surface, warm cases are on average associated with stronger stability than cold cases. To minimize the confounding influence of changes in LTS on cloud-temperature relationships, we required that the temperature difference between $1000 \mathrm{mb}$ and $700 \mathrm{mb}$ be between the 25th and 75th percentiles. For the high-cloud clusters, warm cases tend to occur with 25 a higher tropopause, which allows clouds to extend to greater elevation. To minimize this effect, we required that the temperature difference between $200 \mathrm{mb}$ and $400 \mathrm{mb}$ be between the 25th and 75th percentiles (thus constraining variations in tropopause height). These restrictions were applied independently to each ISCCP gridbox, calendar month, and cluster number with an equal number of warm and cold cases retained.

Cluster analysis of midlatitude oceanic cloud regimes

N. D. Gordon and J. R. Norris

Title Page
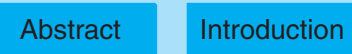

Conclusions

Tables References Figures

14

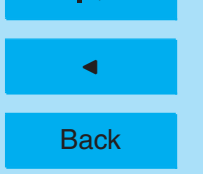

$\rightarrow$

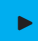

Close

Printer-friendly Version

Interactive Discussion 
Our division of the initial 10 million daily grid box observations into warm and cold subsets for conditions of median advection and lapse rate in three layers of the troposphere left us with about 75000 observations designated as warm and an equal number as cold. Since the warm and cold observations were uniformly distributed ge5 ographically and seasonally in proportion to cluster frequency, our results are globally representative of clouds over midlatitude oceans. Assuming that observations are independent if they are not in adjacent gridboxes and separated by more than one day in time, the effective number of observations, $N_{\text {eff }}$, is about $1 / 4$ of the nominal number of observations, $N$.

\section{Impact of increasing temperature on cloud properties}

Figure 1 shows the mean ISCCP CTP- $\tau$ cloud fraction histograms for each of the seven clusters that were described in Part 1 of this study (reproduced from Fig. 1 of Gordon and Norris, 2010). As explained in the companion paper, we have assigned informal names to each cluster. The first three clusters correspond to low-level cloud 15 regimes and are respectively called "small cumulus", "large cumulus", and "stratocumulus/stratus". Although not apparent in the histogram plot, which shows only the location of cloud top, cluster 4 comprises clouds that extend down to near the surface and is therefore called "deep altostratus". The fifth cluster is "cirrus", and the last two clusters are called "weak frontal" and "strong frontal", respectively, because they are vertically extensive clouds occurring with weak and strong synoptic ascent.

Since we are interested in how cloud properties change with increasing tropospheric temperature, we now examine differences between the warm and cold cases. Figure 2 shows ISCCP CTP- $\tau$ histograms for the average warm minus and cold difference in cloud fraction for each of the seven clusters. Unshaded areas of the histograms represent regions where the difference was not significant at the $95 \%$ confidence level. We calculated confidence levels using a bootstrap method wherein two sets of $N_{\text {eff }}$ values were randomly selected from the combined set of $N$ warm $+N$ cold observations for

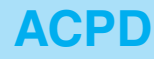

$10,1595-1629,2010$

Cluster analysis of midlatitude oceanic cloud regimes

N. D. Gordon and J. R. Norris

Title Page

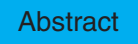

Introduction

Conclusions

Tables

References

Figures

14

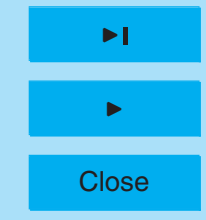

Full Screen / Esc

Printer-friendly Version

Interactive Discussion 
each cluster and the average difference between the two sets was calculated. This procedure was repeated 1000 times to determine how likely the observed difference could have occurred by chance. Table 1 shows cluster average, warm average, cold average, and warm-cold differences in grid box mean cloud properties for each cluster 5 per degree change in temperature. Those differences that are different from zero at the $95 \%$ confidence level are displayed in bold in Table 1. The nonlinear relationship between radiation flux and optical thickness was taken into account by converting cloud optical thickness values to cloud reflectivity at 0.6 microns using an ISCCP look-up table (corresponding to Fig. 3.13 in Rossow et al., 1996) before averaging. The mean 10 reflectivity was then converted back to cloud optical thickness using the same table. This ensures that our cluster mean optical thickness values more correctly represent cloud effects on gridbox-mean visible radiation flux. We also use an ISCCP look-up table (corresponding to Fig. 3.13 in Rossow et al., 1996) to convert visible cloud optical thickness to infrared window cloud emissivity.

15 Figure 2 and Table 1 show a generally consistent reduction in cloud fraction, increase in cloud-top pressure (lowering of cloud-top), and increase in optical thickness across all clusters for increasing temperature. Cluster 1 (Small $\mathrm{Cu}$ ) exhibits the largest decrease in cloud fraction at $-2.3 \% \mathrm{~K}^{-1}$, accompanied by increases in cloud-top pressure and optical thickness. The other low-level cloud clusters (Large $\mathrm{Cu}$ and $\mathrm{Sc} / \mathrm{St}$ ) 20 have smaller reductions in cloud fraction and larger increases in cloud-top pressure (+6.9 and $+9.1 \mathrm{mb} \mathrm{K}^{-1}$, respectively). The enhancement of optical thickness for the small $\mathrm{Cu}$ and Large Cu clusters $\left(+0.13 \mathrm{~K}^{-1}\right.$ and $+0.09 \mathrm{~K}^{-1}$, respectively) is produced by a decrease in the occurrence of optically thin clouds and an increase in the occurrence of optically thick clouds within the grid box (Fig. 2). Cluster $3(\mathrm{Sc} / \mathrm{St})$ is the only 25 cluster with a reduction in optical thickness for increasing temperature $\left(-0.05 \mathrm{~K}^{-1}\right)$, which is due to a decrease in the occurrence of optically thick clouds (Fig. 2).

Cluster 4 (Deep As) shows little change in cloud fraction or cloud-top pressure but has the largest change in optical thickness $\left(+0.33 \mathrm{~K}^{-1}\right)$, as seen in Table 1 . The latter is produced by a decrease in the occurrence of optically thin clouds and an increase in

Cluster analysis of midlatitude oceanic cloud regimes

N. D. Gordon and J. R. Norris

Title Page
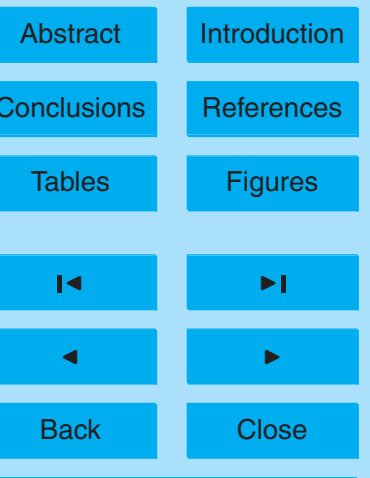

Full Screen / Esc

Printer-friendly Version

Interactive Discussion 
the occurrence of optically thick clouds (Fig. 2). Cluster 5 (Cirrus) exhibits a reduction in cloud fraction $\left(-0.9 \% \mathrm{~K}^{-1}\right)$, and it is the only cluster with a substantial decrease in cloud top pressure $\left(-3.8 \mathrm{mb} \mathrm{K}^{-1}\right)$ caused by a reduction in the occurrence of lowlevel clouds. For the weak frontal cluster, the only significant change with warmer 5 temperature is an increase in optical thickness of $+0.25 \mathrm{~K}^{-1}$ due to the more frequent occurrence of optically thick clouds. The strong frontal cluster exhibits no significant changes with increasing temperature (Table 1).

Although there is substantial noise due to small sample sizes for individual grid boxes, the geographical and seasonal distributions of differences in cloud properties 10 between warm and cold subsets for a given cluster appear to be uniform (not shown). This suggests that the information in Table 1 represents the general response of various cloud regimes to warming rather than a particular response driven by a change only in one region or season.

To provide context for how cloud properties change with temperature, we present the 15 average vertical profiles of meteorological parameters derived from NCEP Reanalysis for the warm and cold subsets of each cluster. Figure 3 shows the vertical profiles of temperature anomalies with respect to grid box and calendar month means. By construction, the warm subset has warmer tropospheric temperature than the cold subset, with the average cluster temperature profile (Fig. 3 from Part 1) lying between them. 20 Although the anomalies are not vertically uniform, the difference between warm and cold profiles is nearly constant within the troposphere, suggesting that the cloud differences cannot be ascribed to differences in lapse rate. Figure 4 shows relative humidity anomalies for warm and cold subsets, and warm cases have a statistically significant greater gridbox relative humidity extending over a larger vertical range than cold cases.

25 The implied increase in geometric thickness for warm subset clouds is consistent with the tendency for larger cloud optical thickness but not with the tendency for greater cloud top pressure (Table 1). Specific humidity anomalies are substantially larger in the lower troposphere for the warm subset (Fig. 5), as may be expected from the increase in saturation specific humidity with increasing temperature. Vertical velocity has

Cluster analysis of midlatitude oceanic cloud regimes

N. D. Gordon and J. R. Norris

Title Page

Abstract

Conclusions

Tables Figures

14

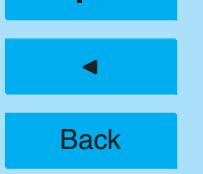

$\rightarrow$

$\checkmark$

Close

Full Screen / Esc

Printer-friendly Version

Interactive Discussion 
a large influence over midlatitude ocean cloudiness (Lau and Crane, 1995; Norris and Klein, 2000; Weaver and Ramanathan, 1997), and Fig. 6 shows that vertical profiles of vertical velocity anomalies are almost exactly the same for warm and cold subsets. This result gives us confidence that our restriction of temperature advection to near5 median values successfully eliminated differences in the large-scale dynamical forcing of clouds in the warm and cold subsets of each cluster.

\section{Impact of increasing temperature on radiative properties}

The effects of temperature modification of cloud properties on the climate system can be better understood by examining changes in radiation flux. Table 2 shows the TOA SW cloud radiative forcing (SWCRF) averaged over the entire cluster, only warm cases, only cold cases, and their difference. Following Ramanathan et al. (1989), we define SWCRF as clear-sky upwelling flux minus all-sky upwelling flux; thus negative values have a cooling effect on climate. In order to understand how changes in cloud fraction and optical thickness separately affect SWCRF, we divide it into the following components,

$\mathrm{SWCRF}=-f \alpha \mathrm{SW} \downarrow^{\mathrm{TOA}}$

$\alpha=\alpha_{\text {overcast }}-\alpha_{\text {clear }}=\frac{\mathrm{SW} \uparrow_{\text {overcast }}^{\mathrm{TOA}}-\mathrm{SW} \uparrow_{\text {clear }}^{\mathrm{TOA}}}{\mathrm{SW} \downarrow^{\mathrm{TOA}}}$

where $f$ is cloud fraction and $\alpha$ is the difference between the albedo of an overcast scene and the clear-sky albedo. Albedo values were obtained by dividing TOA upwelling SW flux by insolation. For all clusters, the changes to clear-sky albedo are smaller than the changes to the albedo of the overcast scene (Table 2). The individual impacts of cloud fraction and albedo changes on SWCRF are defined as follows.

$\Delta \mathrm{SWCRF}_{\mathrm{CF}}=-\Delta f \bar{\alpha} \mathrm{SW} \downarrow^{\mathrm{TOA}}$

Cluster analysis of midlatitude oceanic cloud regimes

N. D. Gordon and J. R. Norris

Title Page

Abstract Introduction

Conclusions

Tables References Figures

14

4

Back

Close

Full Screen / Esc

Printer-friendly Version

Interactive Discussion 
$\Delta \mathrm{SWCRF}_{\alpha}=-\bar{f} \Delta \alpha \mathrm{SW} \downarrow^{\mathrm{TOA}}$

where the overbar indicates the cluster average. $\triangle S W C R F_{C F}$ represents the modification in SWCRF resulting from the warm minus cold difference in cloud fraction multiplied by the average cluster albedo and diurnal insolation, and $\triangle S W C R F_{\alpha}$ represents 5 the modification in SWCRF resulting from the warm minus cold difference in albedo multiplied by average cluster cloud fraction and diurnal insolation. The fact that the sum of $\triangle S W C R F_{C F}$ and $\triangle S_{W C R F}$ is nearly the same as the total change in SWCRF indicates that, within a particular cloud regime, there is little correlation between variability in cloud fraction and variability in cloud albedo. All calculations are conducted 10 such that a positive number represents a net radiative warming of the climate system for an increase in temperature.

For Cluster $1(\mathrm{Small} \mathrm{Cu})$, the radiative warming associated with a reduction in cloud fraction is only partially balanced by a radiative cooling associated with a small increase in albedo/optical thickness, resulting in a total SW radiative warming of $+0.7 \mathrm{~W} \mathrm{~m}^{-2} \mathrm{~K}^{-1}$

15 (Tables 1 and 2). For Cluster 2 (Large $\mathrm{Cu}$ ), the small radiative warming due to a decrease in cloud fraction is contrastingly more than compensated by the radiative cooling from the increased optical thickness of these clouds (total SW radiative cooling is $-0.2 \mathrm{~W} \mathrm{~m}^{-2} \mathrm{~K}^{-1}$ ). The reductions in cloud fraction and optical thickness with increasing temperature for Cluster $3(\mathrm{Sc} / \mathrm{St})$ both contribute to SW radiative warming 20 (total is $+1.2 \mathrm{~W} \mathrm{~m}^{-2} \mathrm{~K}^{-1}$ ). Clusters 4 and 6 (Deep As and Weak Frontal) have the greatest differences in total SW radiative cooling $\left(-1.5\right.$ and $-1.1 \mathrm{~W} \mathrm{~m}^{-2} \mathrm{~K}^{-1}$, respectively), both of which are the result of the increase in cloud optical thickness, but Cluster 7 (Strong Frontal) experiences very little change in SWCRF because its extensive and optically thick clouds are near radiative saturation. The SW radiative warming 25 of $+0.3 \mathrm{~W} \mathrm{~m}^{-2} \mathrm{~K}^{-1}$ for Cluster 5 (Cirrus) primarily results from the reduction of cloud fraction, while changes in optical thickness have small impact.

Our observational method is not a suitable analogue for the global warming scenario when calculating the difference between the average LWCRF for the warm and cold subsets. This is because tropospheric temperature differences are substantially larger

Cluster analysis of midlatitude oceanic cloud regimes

N. D. Gordon and J. R. Norris

Title Page

Abstract

Conclusions

Tables

Figures

14

4

Back

Introduction
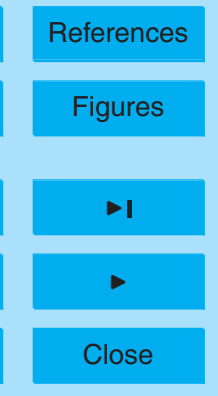

Full Screen / Esc

Printer-friendly Version

Interactive Discussion 
than surface temperature differences in our analysis, unlike the more uniform surface and atmospheric warming expected from a doubling of $\mathrm{CO}_{2}$ (IPCC, 2007). Because LW emission is sensitive to temperature, our observational analysis will underestimate the upwelling LW flux from the surface relative to what will happen during future climate 5 change and thus produce biased LWCRF. Despite our inability to quantify the total LW radiative change between warm and cold subsets, we can nonetheless examine changes in components of LWCRF, defined here as the product of cloud fraction and the difference between upwelling TOA clear-sky and overcast LW flux.

$\mathrm{LWCRF}=f\left(\mathrm{LW} \uparrow_{\text {clear }}^{\mathrm{TOA}}-\mathrm{LW} \uparrow_{\text {overcast }}^{\mathrm{TOA}}\right)$

10 Overcast LW flux is defined as follows,

$\mathrm{LW} \uparrow_{\text {overcast }}^{\mathrm{TOA}}=\left(1-g_{\mathrm{ac}}\right)\left[\varepsilon \sigma T_{\mathrm{CT}}^{4}+(1-\varepsilon) \mathrm{LW} \uparrow_{\mathrm{bc}}\right]$

where $g_{\mathrm{ac}}$ is the above-cloud greenhouse parameter, $\varepsilon$ is the cloud emissivity, $\sigma$ is the Stefan-Boltzmann constant, $T_{\mathrm{CT}}$ is the temperature at cloud top, and $\mathrm{LW} \uparrow_{\mathrm{bc}}$ is the upwelling LW flux coming from beneath the cloud. We will not consider how LWCRF 15 may be affected by changes in clear-sky LW flux in the present analysis, which has the advantage of avoiding possible disagreement between the sign of the CRF change and the sign of the cloud feedback that was noted by Soden et al. (2008).

The above-cloud greenhouse parameter accounts for the reduction in upwelling radiation from cloud-top or from the surface and atmosphere below the cloud level. It is similar to the greenhouse parameter devised by Raval and Ramanathan (1989) and Cess and Udelhofen (2003), except that instead of accounting for the ratio in surface and TOA LW flux, we are interested in the ratio of cloud-level and TOA LW flux. The upwelling flux at cloud level is composed of thermal emission by the cloud as well as a portion of LW flux from below transmitted through the cloud. For cloud regimes that have near-unit emissivity, namely Sc/St, Deep As, Weak Frontal, and Strong Frontal, the transmission of below-cloud LW flux will be negligible. Using values of TOA overcast LW flux and $T_{\mathrm{CT}}$ (Table 1), we calculated average $g_{\mathrm{ac}}$ for those four clusters with

Cluster analysis of midlatitude oceanic cloud regimes

N. D. Gordon and J. R. Norris

Title Page

Abstract

Conclusions

Tables

Figures

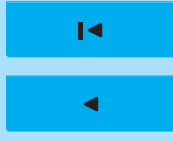

$>1$

Back

Close

Full Screen / Esc

Printer-friendly Version

Interactive Discussion 
$\varepsilon \approx 1$. Figure 7 demonstrates that $g_{\mathrm{ac}}$ varies nearly linearly with cloud-top pressure (i.e., inversely with atmospheric mass above the cloud top). Assuming that this is the only factor controlling $g_{\mathrm{ac}}$, we interpolate the values in Fig. 7 to the average cloud top pressures of the remaining clusters to obtain $g_{\mathrm{ac}}$ for them. With these estimates for the 5 fraction of upwelling radiation absorbed by the atmosphere above the cloud for each cluster, we can use the above formula to calculate the below-cloud LW flux for the three clusters with $\varepsilon<1$ (Table 3 ).

Using cluster average values of LW flux that do not suffer from disproportionate changes in tropospheric and surface temperature, we can calculate the individual im10 pacts of changes in cloud fraction, cloud emissivity, and cloud-top pressure on LWCRF:

$\Delta \mathrm{LWCRF}_{\mathrm{CF}}=\Delta f\left(\overline{\mathrm{LW} \uparrow_{\text {clear }}^{\mathrm{TOA}}-\mathrm{LW} \uparrow_{\text {overcast }}^{\mathrm{TOA}}}\right)$

$\Delta \mathrm{LWCRF}_{\varepsilon}=-\bar{f}\left(1-\overline{g_{\mathrm{ac}}}\right) \Delta \varepsilon\left[\sigma \bar{T}_{\mathrm{CT}}^{4}-\overline{\mathrm{LW}_{\mathrm{bc}}}\right]$

$\Delta \mathrm{LWCRF}_{\mathrm{CTP}}=-\bar{f}\left(1-\overline{g_{\mathrm{ac}}}\right)\left[4 \bar{\varepsilon} \sigma \bar{T}_{\mathrm{CT}}^{3} \overline{d T / d p} \Delta p_{\mathrm{CT}}\right]$

As before, the overbar indicates cluster averages and the $\Delta$ indicates the difference be15 tween warm and cold subsets. The change in cloud top pressure $\Delta p_{\mathrm{CT}}$ was converted to a change in cloud top temperature using cluster average lapse rate from the NCEP reanalysis. Values for $\Delta \mathrm{LWCRF}_{\mathrm{CF}}, \Delta \mathrm{LWCRF}_{\varepsilon}$, and $\triangle \mathrm{LWCRF}_{\mathrm{CTP}}$ are displayed in Table 4 . The consistent reduction in cloud fraction with increasing temperature across clusters results in a negative change to LWCRF, which acts as a cooling effect on the cli20 mate. Enhanced cloud emissivity (parallel to enhanced visible cloud optical thickness) with warming reduces the transmission of upwelling LW flux through those clouds with $\varepsilon<1$ and produces a positive change in LWCRF, with the largest modification for the Cirrus regime, which is also the cluster with the smallest mean emissivity. The largest contribution to changes in LWCRF come from shifts in cloud-top pressure. The three

Cluster analysis of midlatitude oceanic cloud regimes

N. D. Gordon and J. R. Norris

Title Page

Abstract Introduction

Conclusions

Tables

References

Figures

14

4

Back

Close

Full Screen / Esc

Printer-friendly Version

Interactive Discussion 
low-level clusters exhibit a lowering of cloud top, leading to greater LW emission and a negative change in LWCRF, but the Cirrus cluster shows a rising cloud top, leading to less LW emission and a positive change in LWCRF.

Assuming that variations in cloud fraction, cloud emissivity, and cloud top pres5 sure are uncorrelated within each cluster, we can sum their individual contributions to LWCRF to obtain an approximation of the total LWCRF change associated with the difference between the warm and cold subsets. These are listed in Table 5, and indicate that the Cirrus cluster $\left(+1.0 \mathrm{~W} \mathrm{~m}^{-2} \mathrm{~K}^{-1}\right)$ has the largest positive change in LWCRF for increasing temperature, corresponding to a warming effect on the climate system.

10 The others clusters exhibit either a weakly positive or largely negative change (nearzero to $-1.5 \mathrm{~W} \mathrm{~m}^{-2} \mathrm{~K}^{-1}$ ). For the low-level clusters, the summed $\mathrm{LW}$ radiative cooling values are larger than any of the total SW radiative heating values, resulting in net radiative cooling for all low-level cloud regimes $\left(-0.4,-0.9\right.$, and $-0.3 \mathrm{~W} \mathrm{~m}^{-2} \mathrm{~K}^{-1}$ for Small $\mathrm{Cu}$, Large $\mathrm{Cu}$, and $\mathrm{Sc} / \mathrm{St}$, respectively). LW radiative changes are very small for the Deep As and Weak Frontal clusters, and SW radiative cooling due to enhanced optical thickness dominates to produce net radiative cooling for these cloud regimes $\left(-1.1\right.$ and $-1.0 \mathrm{~W} \mathrm{~m}^{-2} \mathrm{~K}^{-1}$ for Deep As and Weak Frontal, respectively). LW, SW, and net radiative effects are small for the Strong Frontal cloud regime, and Cirrus is the only cloud regime for which there is both $\mathrm{LW}$ and SW radiative warming for increasing temperature (net value is $+1.3 \mathrm{~W} \mathrm{~m}^{-2} \mathrm{~K}^{-1}$ ). The only clusters that have a change in total LWCRF that is distinct from zero at the 95\% confidence level are the Large $\mathrm{Cu}$ and $\mathrm{Sc} / \mathrm{St}$ clusters. When averaged over all clusters with weighting by frequency of cluster occurrence, the net radiative difference between warm and cold subsets is $-0.5 \mathrm{~W} \mathrm{~m}^{-2} \mathrm{~K}^{-1}$, however this is not a statistically significant change.

\section{Discussion}

The broad results of the preceding analysis suggest that a warmer troposphere promotes reduced cloud fraction, enhanced cloud optical thickness, a lower cloud top for

Cluster analysis of midlatitude oceanic cloud regimes

N. D. Gordon and J. R. Norris

Title Page

Abstract

Conclusions

Tables

Figures

14

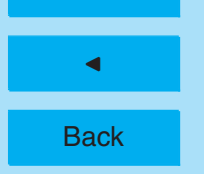

$\rightarrow$

$\checkmark$

Close 
low-level clouds, and a higher cloud top for cirrus over the midlatitude ocean. Since this study was constructed to eliminate variations in temperature associated with horizontal and vertical advection along with variations in lapse rate, we presume that the observed changes are directly connected to increased temperature rather than large-

5 scale dynamical processes. The reduction in cloud fraction with warmer temperature is consistent with the findings of previous investigations of cloud-temperature relationships over midlatitude oceans (Norris and Leovy, 1994; Weare, 1994; Norris and lacobellis, 2005; Wagner et al., 2008), but the enhancement of cloud optical thickness is possibly not. Williams and Webb (2009), using a clustering routine to examine the re10 sponse of GCM-simulated cloud regimes to a doubling of $\mathrm{CO}_{2}$, found that most models produced a shift towards optically thicker low-level clouds and more elevated high-level clouds with warming in the ice-free extratropics.

Theory suggests that adiabatic cloud liquid water content will increase with temperature as a result in the increase in saturation vapor pressure, particularly at middle and 15 high (Somerville and Remer, 1984; Betts and Harshvardhan, 1987). The conversion of ice to liquid at warmer temperature in mixed-phased clouds is also expected to enhance optical thickness at middle latitudes because cloud droplets have smaller size and fall out more slowly than ice crystals (Mitchell et al., 1989). Contrastingly, previous observational work using the same satellite cloud dataset as in this study indicates that cloud 20 optical thickness decreases with temperature over the midlatitude North Pacific (Norris and lacobellis, 2005). Tselioudis et al. (1992) also reported a decrease in optical thickness with temperature for midlatitude oceanic low-level clouds warmer than $-10^{\circ} \mathrm{C}$, even when partially cloud-filled pixel effects are taken into account (Chang and Coakley, 2007). Two of the low-level cloud clusters examined in this study (Small $\mathrm{Cu}$ and 25 Large $\mathrm{Cu}$ ) exhibit an increase in optical thickness with temperature, and the third cluster (Sc/St) shows a decrease smaller than that reported by Tselioudis et al. (1992). These apparently discrepant results can be reconciled by keeping in mind that our study calculated the partial derivative of cloud properties with respect to temperature, whereas the other studies calculated the total derivative. If large-scale dynamical processes

Cluster analysis of midlatitude oceanic cloud regimes

N. D. Gordon and J. R. Norris

Title Page

Abstract

Conclusions

Tables Figures

14

4

Back

Introduction

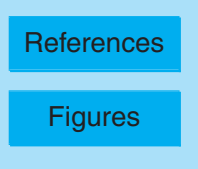

$\rightarrow$

$>$

Close

Printer-friendly Version

Interactive Discussion

1611 
happen to reduce cloud optical thickness, while coincidently enhancing temperature, that would create a negative, rather than positive, correlation. In the case of Norris and lacobellis (2005), it is likely that constraining vertical velocity only at $500 \mathrm{mb}$ and advection only near the surface were insufficient to remove joint dynamical influences 5 on cloudiness and temperature.

The presence of dynamics may also explain why Norris and lacobellis (2005), Chang and Coakley (2007), Wagner et al. (2008) report that warmer temperatures are often associated with higher cloud tops, a result opposite our finding for low-level clouds. Another possibility is inaccurate or imprecise retrievals of average cloud top pressure 10 for a grid box with clouds at different levels.

Except for Cirrus, all cloud regimes over midlatitude oceans exhibit upwelling net radiation flux at TOA that is larger for the warm subset than for the cold subset. This result implies that, in terms of the direct response to temperature change, clouds exert a weak negative feedback on the climate system. As the atmosphere warms due to increasing anthropogenic greenhouse gas concentrations, the increase in temperature modifies cloud properties such that more radiation goes out to space, thus mitigating the anthropogenic greenhouse radiative forcing. It is essential to keep in mind, however, that this does not mean the total midlatitude ocean cloud feedback on the climate system is negative because increasing temperature could also produce a change in atmospheric circulation that more strongly modifies cloud properties such that overall upwelling net radiation flux is reduced (e.g., a positive feedback). One potential positive feedback would be a poleward shift in the storm track and associated cloudiness that moves high-albedo clouds to a latitude where there is less insolation and thus less reflection back to space (e.g., Weaver, 2003). For subtropical low-level clouds, it appears that dynamical processes play a large role in producing a positive total cloud feedback on decadal and longer time scales (Clement et al., 2009).

\section{ACPD}

10, 1595-1629, 2010

Cluster analysis of midlatitude oceanic cloud regimes

N. D. Gordon and J. R. Norris

Title Page

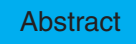

Introduction

Conclusions

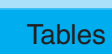

References

Tables

Figures

14

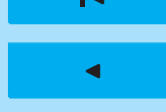

Back

Close

Full Screen / Esc

Printer-friendly Version

Interactive Discussion 


\section{Conclusions}

Part 1 of this study applied a $k$-means clustering algorithm to 21 years of ISCCP daily satellite gridbox values over midlatitude oceans to partition the data into seven groups, each representing a different cloud regime with a unique suite of dynamics. In or-

5 der of decreasing frequency of occurrence, we informally called these clusters Small $\mathrm{Cu}$, Large $\mathrm{Cu}, \mathrm{Sc} / \mathrm{St}$, Deep As, Cirrus, Weak Frontal, and Strong Frontal, based on their cloud and meteorological characteristics. In Part 2 of this study, we divided these relatively homogeneous clusters into a warm subset and cold subset according to tropospheric temperature anomalies with uniform sampling over grid boxes and calendar months. For each cluster, we constrained vertical and horizontal temperature advection to have near-median values at three different levels in the troposphere and constrained lapse rate to have near-median values in the lower troposphere and in the tropopause region. This enabled us to isolate changes in cloud properties as a direct response to increasing temperature from changes in cloud properties in response to dynamical forcing that also were associated with a change in temperature.

Negligible change in cloud fraction is seen for the Deep As and two Frontal regimes, but for the rest of the clusters, the warm subset consistently exhibits less cloud fraction than the cold subset. No change in optical depth is seen for the Strong Frontal regime, but for all of the other clusters except for $\mathrm{Sc} / \mathrm{St}$, the warm subset consistently has greater optical depth than the cold subset. The changes in cloud-top pressure are less consistent, with the three low-level clusters (Small $\mathrm{Cu}$, Large $\mathrm{Cu}$, and $\mathrm{Sc} / \mathrm{St}$ ) showing greater cloud top pressure for the warm subset and the Cirrus cluster showing greater cloud top pressure for the cold subset. We then used ISCCP flux data to examine how these changes in cloud properties with increasing temperature affected upwelling SW and LW radiative flux at the top of the atmosphere. The reduction of cloud fraction at warmer temperature allows more SW radiation to be absorbed by the Earth, but this is partially or wholly canceled by less absorption of outgoing LW radiation. The enhancement of optical thickness at warmer temperature increases the reflection of SW 
radiation back to space, although this is partially canceled by less transmission of LW radiation through clouds for those cloud regimes with emissivity less than zero (Small $\mathrm{Cu}$, Large $\mathrm{Cu}$, and Cirrus). The decrease in cloud top height at warmer temperature for the low-level clusters increases LW emission by the clouds, and the increase in 5 cloud top height for Cirrus decreases LW emission. Net upwelling radiation increases at warmer temperature for every cluster except Cirrus.

Averaged over all clusters with weighting by frequency of occurrence, the increase in upwelling flux is about $0.5 \mathrm{~W} \mathrm{~m}^{-2} \mathrm{~K}^{-1}$, implying that the direct response of midlatitude oceanic clouds to warmer temperature acts as a negative feedback on the climate system (e.g., partially canceling the reduction in upwelling LW flux caused by increasing greenhouse gas concentrations). This result, however, does not mean the total cloud feedback by midlatitude oceanic clouds is negative. A change in atmospheric mean circulation and variability caused by anthropogenic greenhouse warming could produce dynamical forcing of clouds that overwhelms the temperature response and generates 15 a positive feedback. More research is needed to determine what changes in atmospheric dynamics are likely to accompany climate change. The cloud-temperaturedynamical relationships revealed in this study and its companion could provide a useful diagnostic tool for the evaluation of global climate models.

Acknowledgements. This work was supported by NSF CAREER Grant AM02-38257 and 20 NASA Grant GWEC NAG5-11731. The authors thank Steve Klein for useful comments.

\section{References}

Betts, A. K. and Harshvardhan: Thermodynamic constraint on the cloud liquid water feedback in climate models, J. Geophys. Res., 92, 8483-8485, 1987.

Bony, S., Lau, K.-M., and Sud, Y. C.: Sea surface temperature and large-scale circulation influences on tropical greenhouse effect and cloud radiative forcing, J. Climate, 10, 20552077, 1997.

Bony, S., Dufresne, J.-L., Le Treut, H., Morcrette, J.-J., and Senior, C.: On dynamic and thermodynamic components of cloud changes, Clim. Dynam., 22, 71-86, 2004.

Cluster analysis of midlatitude oceanic cloud regimes

N. D. Gordon and J. R. Norris

Title Page

Abstract

Conclusions

Tables

Figures

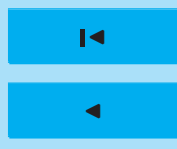

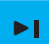

Back

Close

Full Screen / Esc

Printer-friendly Version

Interactive Discussion 
Cess, R. D. and Udelhofen, P. M.: Climate change during 1985-1999: cloud interactions determined from satellite measurements, Geophys. Res. Lett., 30, 1019, doi:10.1029/2002GL016128, 2003.

Cess, R. D., Harrison, E. F., Minnis, P., Barkstrom, B. R., Ramanathan, V., and Kwon, T. Y.: Interpretation of seasonal cloud-climate interactions using Earth Radiation Budget Experiment data, J. Geophys. Res., 97, 7613-7617, 1992.

Chang, F.-L. and Coakley, J. A.: Relationships between marine stratus cloud optical depth and temperature: inferences from AVHRR observations, J. Climate, 20, 2022-2036, 2007.

Clement, A. C., Burgman, R., and Norris, J. R.: Observational and model evidence for positive low-level cloud feedback, Science, 325, 460-426, 2009.

Gordon, N. D., Norris, J. R., Weaver, C. P., and Klein, S. A.: Cluster analysis of cloud regimes and characteristic dynamics of midlatitude synoptic systems in observations and a model, J. Geophys. Res., 110, D15S17, doi:10.1029/2004JD005027, 2005.

Gordon, N. D. and Norris, J. R.: Cluster analysis of midlatitude oceanic cloud regimes - Part 1:

15 Mean cloud and meteorological properties, Atmos. Chem. Phys. Discuss., 10, 1559-1593, 2010,

http://www.atmos-chem-phys-discuss.net/10/1559/2010/.

Hartigan, J. A.: Clustering Algorithms, Wiley Press, New York, NY, 351 pp., 1975.

IPCC Climate Change 2007: The Physical Science Basis, Contribution of Working Group I to the Fourth Assessment Report of the Intergovernmental Panel on Climate Change, edited by: Solomon, S., Qin, D., Manning, M., Chen, Z., Marquis, M., Averyt, K. B., Tignor, M., and Miller, H. L., Cambridge University Press, Cambridge, UK and New York, NY, USA, 996 pp., 2007.

Jakob, C. and Tselioudis, G.: Objective identification of cloud regimes in the Tropical West Pacific, Geophys. Res. Lett., 30(21), 2082, doi:10.1029/2003GL018367, 2003.

Jakob, C., Tselioudis, G., and Hume T.: The radiative, cloud and thermodynamic properties of the major Tropical Western Pacific cloud regimes, J. Climate, 18, 1203-1215, 2005.

Kalnay, E., Kanamitsu, M., Kistler, R., Collins, W., Deaven, D., Gandin, L., Iredell, M., Saha, S., White, G., Woollen, J., Zhu, Y., Chelliah, M., Ebisuzaki, W., Higgins, W., Janowiak, J.,

so Mo, K. C., Ropelewski, C., Wang, J., Leetmaa, A., Reynolds, R., Jenne, R., and Joseph, D.: The NCEP/NCAR 40-year reanalysis project, B. Am. Meteorol. Soc., 77, 437-470, 1996.

Klein, S. A. and Hartmann, D. L.: The seasonal cycle of low stratiform clouds, J. Climate, 6 , 1587-1606, 1993.

10, 1595-1629, 2010

Cluster analysis of midlatitude oceanic cloud regimes

N. D. Gordon and J. R. Norris

Title Page

Abstract

Introduction

Conclusions

References

Tables

Figures

14

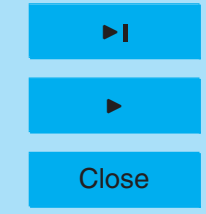

Full Screen / Esc

Printer-friendly Version

Interactive Discussion 
Lau, N.-C. and Crane, M. W.: A satellite view of the synoptic-scale organization of cloud cover in midlatitude and tropical circulation systems, Mon. Weather Rev., 123, 1984-2006, 1995.

Mitchell, J. F. B., Senior, C. A., and Ingram, W. J.: $\mathrm{CO}_{2}$ and climate: a missing feedback?, Nature, 341, 132-134, 1989.

5 Norris, J. R.: Low cloud type over the ocean from surface observations, Part I: Relationship to surface meteorology and the vertical distribution of temperature and moisture, J. Climate, 11, 369-382, 1998.

Norris, J. R.: Interannual and interdecadal variability in the storm track, cloudiness, and sea surface temperature over the summertime North Pacific, J. Climate, 13, 422-430, 2000.

10 Norris, J. R. and Leovy, C. B.: Interannual variability in stratiform cloudiness and sea surface temperature, J. Climate, 7, 1915-1925, 1994.

Norris, J. R. and Klein, S. A.: Low cloud type over the ocean from surface observations, Part III: Relationship to vertical motion and the regional surface synoptic environment, J. Climate, 13, 245-256, 2000.

Norris, J. R. and lacobellis, S. F.: North Pacific cloud feedbacks inferred from synoptic-scale dynamic and thermodynamic relationships, J. Climate, 18, 4862-4878, 2005.

Ramanathan, V., Barkstrom, B. R., and Harrison E. F.: Climate and the earth's radiation budget, Phys. Today, 42(5), 22-33, 1989.

Raval, A. and Ramanathan, V.: Observational determination of the greenhouse effect, Nature, 342, 758-761, 1989.

Ringer, M. A., McAvaney, B. J., Andronova, N., Buja, L. E., Esch, M., Ingram, W. J., Li, B., Quaas, J., Roeckner, E., Senior, C. A., Soden, B. J., Volodin, E. M., Webb, M. J., and Williams, K. D.: Global mean cloud feedbacks in idealized climate change experiments, Geophys. Res. Lett., 33(7), L07718, doi:10.1029/2005GL025370, 2006.

Rossow, W. B., Walker, A. W., Beuschel, D. E., and Roiter, M. D.: International Satellite Cloud Climatology Project (ISCCP) Documentation of New Cloud Datasets, WMO/TD-No. 737, World Meteorological Organization, 115 pp., 1996.

Rossow, W. B. and Schiffer, R. A.: Advances in understanding ISCCP, B. Am. Meteorol. Soc., 80, 2261-2287, 1999.

30 Soden, B. J. and Held, I. M.: An assessment of climate feedbacks in coupled ocean-atmosphere models, J. Climate, 19, 3354-3360, 2006.

Soden, B. J., Held, I. M., Colman, R., Shell, K. M., Kiehl, J. T., and Shields, C. A.: Quantifying climate feedbacks using radiative kernels, J. Climate, 21, 3504-3520, 2008.

Cluster analysis of midlatitude oceanic cloud regimes

N. D. Gordon and J. R. Norris

Title Page

Abstract

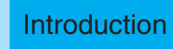

Conclusions

Tables

References

Figures

14

4

Back

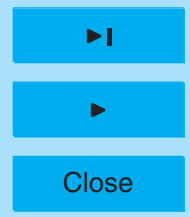

Full Screen / Esc

Printer-friendly Version

Interactive Discussion 
Somerville, R. C. J. and Remer, L. A.: Cloud optical thickness feedbacks in the $\mathrm{CO}_{2}$ climate problem, J. Geophys. Res., 89, 9668-9672, 1984.

Tian, B. and Ramanathan, V.: Role of clouds in surface and atmospheric energy budget, J. Climate, 15, 296-305, 2002.

5 Tselioudis, G., Rossow, W. B., and Rind, D.: Global patterns of cloud optical thickness variation with temperature, J. Climate, 5, 1484-1495, 1992.

Wagner, T., Beirle, S., Deutschmann, T., Grzegorski, M., and Platt, U.: Dependence of cloud properties derived from spectrally resolved visible satellite observations on surface temperature, Atmos. Chem. Phys., 8, 2299-2312, 2008,

$10 \mathrm{http}: / /$ www.atmos-chem-phys.net/8/2299/2008/.

Weaver, C. P. and Ramanathan, V.: The link between summertime cloud radiative forcing and extratropical cyclones in the North Pacific, J. Climate, 9, 2093-2109, 1996.

Weaver, C. P. and Ramanathan, V.: Relationships between large-scale vertical velocity, static stability, and cloud radiative forcing over Northern Hemisphere extratropical oceans, J. Climate, 10, 2871-2887, 1997.

Weaver, C. P.: Efficiency of storm tracks an important climate parameter? The role of cloud radiative forcing in poleward heat transport, J. Geophys. Res., 108(D1), 4018, doi:10.1029/2002JD002756, 2003.

Webb, M. J., Senior, C. A., Sexton, D. M. H., Ingram, W. J., Williams, K. D., Ringer, M. A., McAvaney, B. J., Colman, R., Soden, B. J., Gudgel, R., Knutson, T., Emori, S., Ogura, T., Tsushima, Y., Andronova, N., Li, B., Musat, I., Bony, S., and Taylor, K. E.: On the contribution of local feedback mechanisms to the range of climate sensitivity in two GCM ensembles, Clim. Dynam., 27(1), 17-38, 2006.

Williams K. D. and Tselioudis, G.: GCM intercomparison of global cloud regimes: Present-day evaluation and climate change response, Clim. Dynam., 29, 231-250, 2007.

Williams, K. D. and Webb, M. J.: A quantitative performance assessment of cloud regimes in climate models, Clim. Dynam., 33, 141-157, 2009.

Zhang, Y., Rossow, W. B., Lacis, A. A., Oinas, V., and Mishchenko, M. I.: Calculation of radiative fluxes from the surface to top of atmosphere based on ISCCP and other global data sets: refinements of the radiative transfer model and the input data, J. Geophys. Res., 109, D19105, doi:10.1029/2003JD004457, 2004.

Cluster analysis of midlatitude oceanic cloud regimes

N. D. Gordon and J. R. Norris

Title Page

Abstract Introduction

Conclusions

Tables

References

Figures

14

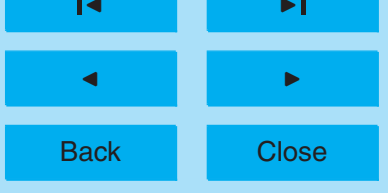

Full Screen / Esc

Printer-friendly Version

Interactive Discussion 


\section{ACPD}

$10,1595-1629,2010$

Table 1. Average cloud properties for the entire cluster, warm subset, cold subset, and the difference between the two divided by the temperature change for each cluster (Subsets different at the $95 \%$ confidence level are in bold).

\begin{tabular}{|c|c|c|c|c|c|c|c|}
\hline & $\begin{array}{r}1-\text { Small } \\
\mathrm{Cu}\end{array}$ & $\begin{array}{r}2 \text { - Large } \\
\mathrm{Cu}\end{array}$ & $3-\mathrm{Sc} / \mathrm{St}$ & $\begin{array}{r}4-\text { Deep } \\
\text { As }\end{array}$ & $5-\mathrm{Ci}$ & $\begin{array}{r}6 \text { - Weak } \\
\text { Frontal }\end{array}$ & $\begin{array}{r}7 \text { - Strong } \\
\text { Frontal }\end{array}$ \\
\hline Cluster Frequency (\%) & 27.5 & 18.4 & 16.5 & 14.0 & 11.3 & 7.7 & 4.3 \\
\hline Warm-Cold Difference (K) & 2.25 & 2.23 & 2.25 & 2.58 & 2.37 & 2.45 & 2.37 \\
\hline $\begin{array}{l}\text { Cluster Cloud Fraction (\%) } \\
\text { Warm Subset (\%) } \\
\text { Cold Subset }(\%)\end{array}$ & $\begin{array}{l}54.1 \\
45.5 \\
50.7\end{array}$ & $\begin{array}{l}77.8 \\
75.8 \\
77.1\end{array}$ & $\begin{array}{l}92.9 \\
92.0 \\
92.9\end{array}$ & $\begin{array}{l}97.5 \\
97.7 \\
97.9\end{array}$ & $\begin{array}{l}87.4 \\
85.0 \\
87.0\end{array}$ & $\begin{array}{l}99.0 \\
99.3 \\
99.4\end{array}$ & $\begin{array}{l}99.4 \\
99.5 \\
99.5\end{array}$ \\
\hline Difference $\left(\% \mathrm{~K}^{-1}\right)$ & -2.3 & -0.6 & -0.4 & -0.1 & -0.9 & 0.0 & 0.0 \\
\hline $\begin{array}{l}\text { Cluster CTP }(\mathrm{mb}) \\
\text { Warm Subset }(\mathrm{mb}) \\
\text { Cold Subset (mb) }\end{array}$ & $\begin{array}{l}658.2 \\
679.2 \\
668.7\end{array}$ & $\begin{array}{l}781.0 \\
799.2 \\
783.8\end{array}$ & $\begin{array}{l}776.4 \\
795.0 \\
774.5\end{array}$ & $\begin{array}{l}584.3 \\
588.1 \\
589.5\end{array}$ & $\begin{array}{l}431.8 \\
425.2 \\
434.1\end{array}$ & $\begin{array}{l}382.6 \\
389.1 \\
388.5\end{array}$ & $\begin{array}{l}347.6 \\
350.9 \\
349.0\end{array}$ \\
\hline Difference $\left(\mathrm{mb} \mathrm{K}^{-1}\right)$ & +4.6 & +6.9 & +9.1 & -0.5 & -3.8 & +0.3 & +0.8 \\
\hline $\begin{array}{l}\text { Cluster Optical Thickness } \\
\text { Warm Subset } \\
\text { Cold Subset }\end{array}$ & $\begin{array}{l}3.63 \\
3.32 \\
3.03\end{array}$ & $\begin{array}{l}2.89 \\
2.89 \\
2.69\end{array}$ & $\begin{array}{l}7.19 \\
7.07 \\
7.19\end{array}$ & $\begin{array}{l}8.30 \\
8.30 \\
7.46\end{array}$ & $\begin{array}{l}2.30 \\
2.12 \\
2.06\end{array}$ & $\begin{array}{l}8.90 \\
9.06 \\
8.44\end{array}$ & $\begin{array}{l}23.08 \\
22.63 \\
22.63\end{array}$ \\
\hline Difference $\left(\mathrm{K}^{-1}\right)$ & +0.13 & +0.09 & -0.05 & +0.33 & +0.03 & +0.25 & 0.00 \\
\hline $\begin{array}{l}\text { Cluster Emissivity } \\
\text { Warm Subset } \\
\text { Cold Subset }\end{array}$ & $\begin{array}{l}0.835 \\
0.825 \\
0.802\end{array}$ & $\begin{array}{l}0.823 \\
0.823 \\
0.805\end{array}$ & $\begin{array}{l}0.979 \\
0.979 \\
0.978\end{array}$ & $\begin{array}{l}0.985 \\
0.986 \\
0.981\end{array}$ & $\begin{array}{l}0.776 \\
0.750 \\
0.746\end{array}$ & $\begin{array}{l}0.993 \\
0.994 \\
0.992\end{array}$ & $\begin{array}{l}1.000 \\
1.000 \\
1.000\end{array}$ \\
\hline Difference $\left(\mathrm{K}^{-1}\right)$ & +0.010 & +0.008 & 0.000 & +0.002 & +0.002 & +0.001 & 0.000 \\
\hline
\end{tabular}

Cluster analysis of midlatitude oceanic cloud regimes

N. D. Gordon and J. R. Norris

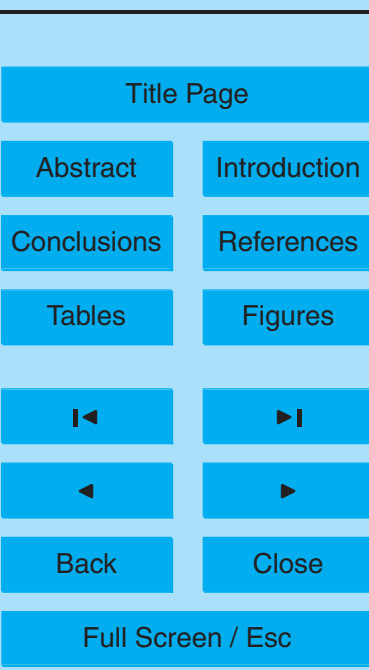

Printer-friendly Version

Interactive Discussion 


\section{ACPD}

10, 1595-1629, 2010

Table 2. Average total SWCRF, SWCRF from cloud fraction change, and SWCRF from albedo change for entire the cluster, warm subset, cold subset, and the difference between the two (per degree temperature change; Subsets different at the 95\% confidence level are in bold).

\begin{tabular}{lrrrrrrr}
\hline & $\begin{array}{r}\text { 1- Small } \\
\mathrm{Cu}\end{array}$ & $\begin{array}{r}2-\text { Large } \\
\mathrm{Cu}\end{array}$ & $3-\mathrm{Sc} / \mathrm{St}$ & $\begin{array}{r}4-\text { Deep } \\
\text { As }\end{array}$ & $5-\mathrm{Ci}$ & $\begin{array}{r}\text { 6- Weak } \\
\text { Frontal }\end{array}$ & $\begin{array}{r}7-\text { Strong } \\
\text { Frontal }\end{array}$ \\
\hline Cluster Total SWCRF $\left(\mathrm{W} \mathrm{m}^{-2}\right)$ & -39.0 & -40.5 & -97.0 & -112.9 & -55.0 & -123.1 & -168.4 \\
Warm Subset $\left(\mathrm{W} \mathrm{m}^{-2}\right)$ & -30.8 & -38.8 & -93.9 & -113.1 & -51.1 & -125.2 & -167.1 \\
Cold Subset $\left(\mathrm{W} \mathrm{m}^{-2}\right)$ & -32.3 & -38.5 & -96.6 & -109.3 & -51.8 & -122.6 & -167.2 \\
Difference $\left(\mathrm{W} \mathrm{m}^{-2} \mathrm{~K}^{-1}\right)$ & $+\mathbf{0 . 7}$ & -0.2 & $+\mathbf{1 . 2}$ & -1.5 & +0.3 & -1.1 & +0.1 \\
SWCRF $_{\mathrm{CF}}$ & & & & & & & \\
Warm Subset $\left(\mathrm{W} \mathrm{m}^{-2}\right)$ & -25.7 & -36.7 & -95.3 & -111.13 & -47.3 & -117.3 & -162.8 \\
Cold Subset $\left(\mathrm{W} \mathrm{m}^{-2}\right)$ & -28.6 & -37.3 & -96.3 & -111.35 & -48.5 & -117.4 & -162.8 \\
Difference $\left(\mathrm{W} \mathrm{m}^{-2}\right)$ & +1.3 & +0.3 & +0.5 & +0.1 & +0.5 & +0.1 & 0.0 \\
SWCRF & & & & & & & \\
Warm Subsed $\left(\mathrm{W} \mathrm{m}^{-2}\right)$ & -27.5 & -37.4 & -95.0 & -113.2 & -48.0 & -118.7 & -162.7 \\
Cold Subset $\left(\mathrm{W} \mathrm{m}^{-2}\right)$ & -26.8 & -36.5 & -96.6 & -109.3 & -47.9 & -116.1 & -162.8 \\
Difference $\left(\mathrm{W} \mathrm{m}^{-2}\right)$ & -0.3 & -0.4 & +0.7 & -1.5 & 0.0 & -1.1 & +0.1 \\
\hline
\end{tabular}

\section{Cluster analysis of midlatitude oceanic cloud regimes}

N. D. Gordon and J. R. Norris

\section{Title Page}

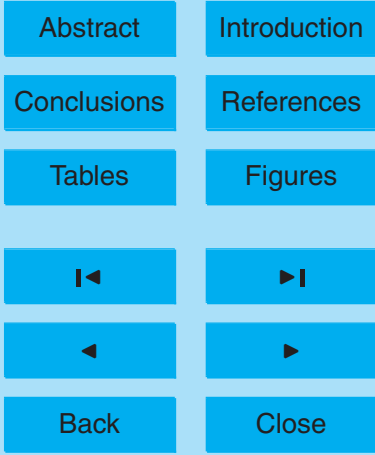

Full Screen / Esc

Printer-friendly Version

Interactive Discussion 


\section{ACPD}

10, 1595-1629, 2010

\section{Cluster analysis of} midlatitude oceanic cloud regimes

N. D. Gordon and J. R. Norris

Table 3. Below-cloud upwelling LW flux.

\begin{tabular}{cccc}
\hline & $1-$ Small $\mathrm{Cu}$ & $2-$ Large $\mathrm{Cu}$ & 5 - Cirrus \\
\hline Cluster $\mathrm{LW}_{\mathrm{bc}}\left(\mathrm{W} \mathrm{m}^{-2}\right)$ & 305.0 & 357.7 & 338.0
\end{tabular}

Title Page

Abstract Introduction

Conclusions

References

Tables

Figures

14

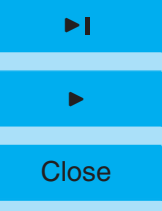

Back

Full Screen / Esc

Printer-friendly Version

Interactive Discussion 


\section{ACPD}

10, 1595-1629, 2010

\section{Cluster analysis of} midlatitude oceanic cloud regimes

N. D. Gordon and J. R. Norris

Table 4. Average LWCRF from cloud fraction change, LWCRF from emissivity change, and LWCRF from cloud-top pressure change for the difference between the warm and cold subsets (per degree temperature change; Subsets different at the 95\% confidence level are in bold).

\begin{tabular}{lccccccc}
\hline & $\begin{array}{c}1-\text { Small } \\
\mathrm{Cu}\end{array}$ & $\begin{array}{c}2-\mathrm{Large} \\
\mathrm{Cu}\end{array}$ & $3-\mathrm{Sc} / \mathrm{St}$ & $\begin{array}{c}4-\text { Deep } \\
\text { As }\end{array}$ & $\begin{array}{c}5-\text { Cirrus } \\
\end{array}$ & $\begin{array}{c}6-\text { Weak } \\
\text { Frontal }\end{array}$ & $\begin{array}{c}7-\text { Strong } \\
\text { Frontal }\end{array}$ \\
\hline$\Delta \mathrm{LWCRF}_{\mathrm{CF}}\left(\mathrm{W} \mathrm{m}^{-2} \mathrm{~K}^{-1}\right)$ & $-\mathbf{0 . 6}$ & -0.1 & -0.1 & 0.0 & $-\mathbf{0 . 5}$ & 0.0 & 0.0 \\
$\Delta \mathrm{LWCRF}_{\varepsilon}\left(\mathrm{W} \mathrm{m}^{-2} \mathrm{~K}^{-1}\right)$ & +0.1 & $+\mathbf{0 . 3}$ & 0.0 & +0.2 & +0.4 & +0.2 & 0.0 \\
$\Delta \mathrm{LWCRF}_{\mathrm{CTT}}\left(\mathrm{W} \mathrm{m}^{-2} \mathrm{~K}^{-1}\right)$ & $-\mathbf{0 . 5}$ & $-\mathbf{0 . 9}$ & $-\mathbf{1 . 4}$ & +0.1 & +1.1 & -0.1 & -0.3 \\
\hline
\end{tabular}

Title Page

Abstract Introduction

Conclusions

Tables

References

Figures

14

4

Back

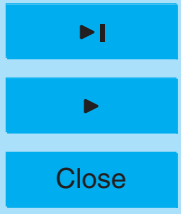

Full Screen / Esc

Printer-friendly Version

Interactive Discussion 


\section{ACPD}

10, 1595-1629, 2010

Table 5. Total SWCRF and sum of LWCRF component changes for each cluster and the average from the midlatitude based on relative frequency of occurrence. (Subsets different at the $95 \%$ confidence level are in bold).

\begin{tabular}{|c|c|c|c|c|c|c|c|c|}
\hline & $\begin{array}{c}1-\text { Small } \\
\mathrm{Cu}\end{array}$ & $\begin{array}{c}2-\text { Large } \\
\mathrm{Cu}\end{array}$ & $3-\mathrm{Sc} / \mathrm{St}$ & $\begin{array}{l}\text { 4- Deep } \\
\text { As }\end{array}$ & $5-$ Cirrus & $\begin{array}{l}6-\text { Weak } \\
\text { Frontal }\end{array}$ & $\begin{array}{l}7 \text { - Strong } \\
\text { Frontal }\end{array}$ & $\begin{array}{l}\text { Midlatitude } \\
\text { Ocean } \\
\text { Average }\end{array}$ \\
\hline Cluster Frequency (\%) & 27.5 & 18.4 & 16.5 & 14.0 & 11.3 & 7.7 & 4.3 & \\
\hline $\begin{array}{l}\text { Sum of LWCRF } \\
\text { components }\left(\mathrm{W} \mathrm{m}^{-2} \mathrm{~K}^{-1}\right)\end{array}$ & -1.1 & -0.7 & -1.5 & +0.3 & +1.0 & +0.1 & -0.3 & \\
\hline $\begin{array}{l}\text { Total SWCRF } \\
\left(\mathrm{W} \mathrm{m}^{-2} \mathrm{~K}^{-1}\right)\end{array}$ & +0.7 & -0.2 & +1.2 & -1.5 & +0.3 & -1.1 & +0.1 & \\
\hline $\begin{array}{l}\text { Net CRF } \\
\left(\mathrm{W} \mathrm{m}^{-2} \mathrm{~K}^{-1}\right)\end{array}$ & -0.4 & -0.9 & -0.3 & -1.1 & +1.3 & -1.0 & -0.3 & -0.5 \\
\hline
\end{tabular}

\section{Cluster analysis of midlatitude oceanic cloud regimes}

N. D. Gordon and J. R. Norris

Title Page

Abstract Introduction

Conclusions References

Tables Figures

14

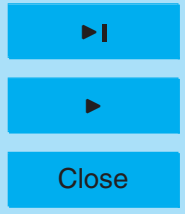

Back

Full Screen / Esc

Printer-friendly Version

Interactive Discussion 

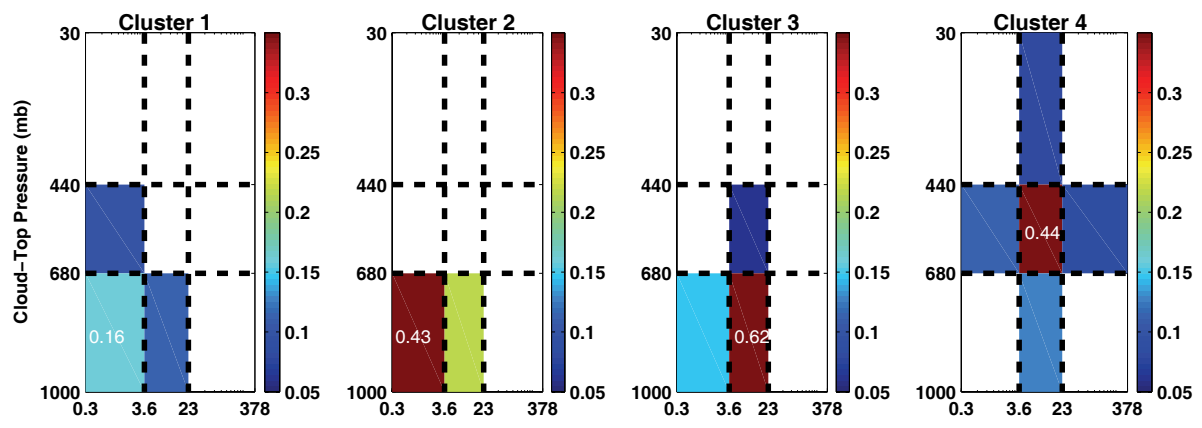

10, 1595-1629, 2010

ACPD

\section{Cluster analysis of} midlatitude oceanic cloud regimes
N. D. Gordon and
J. R. Norris
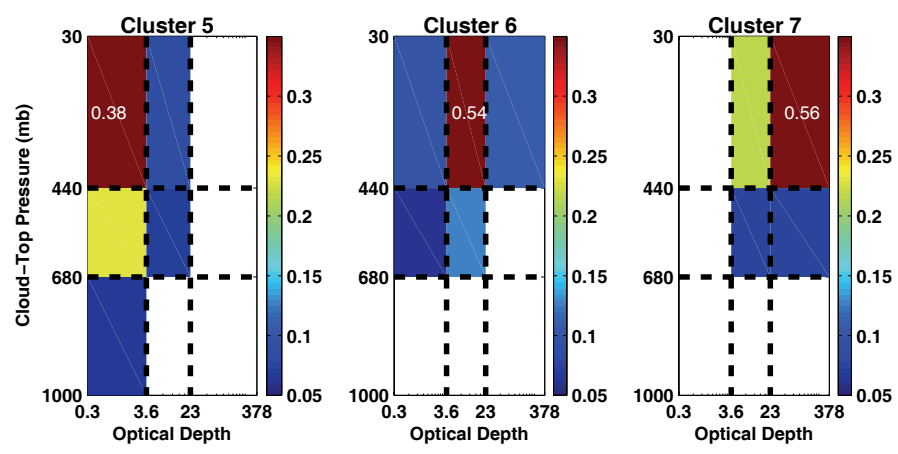

Title Page

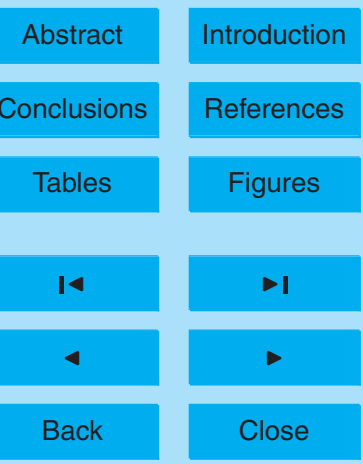

Full Screen / Esc

Fig. 1. Mean ISCCP histograms of cloud fraction for each cloud-top pressure and cloud optical

Printer-friendly Version thickness interval. 

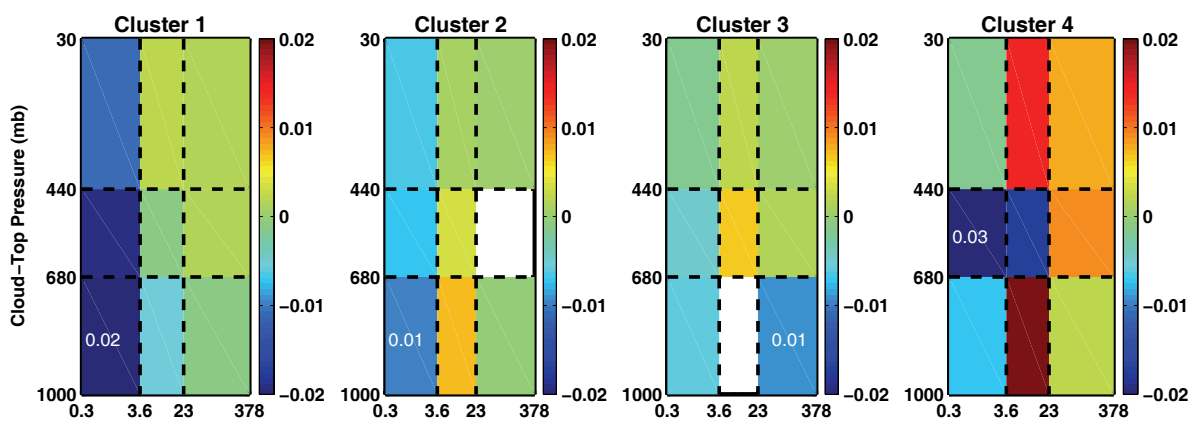

$10,1595-1629,2010$
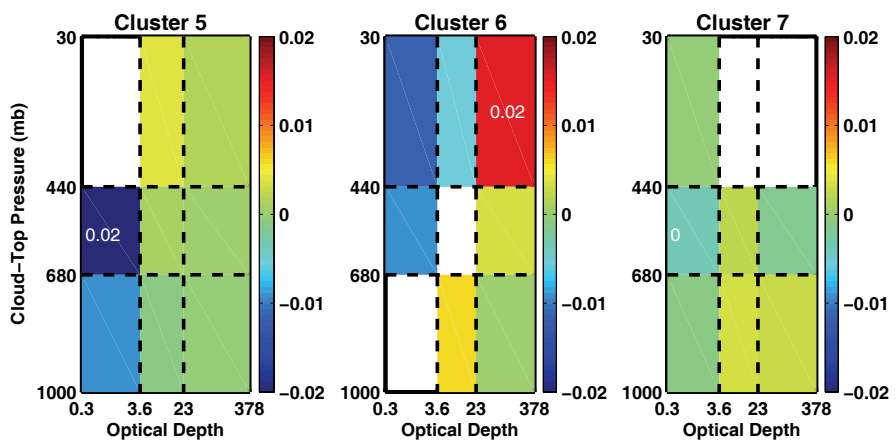

Fig. 2. ISCCP histograms of difference in cloud fraction between warm and cold subsets for each cluster.

Cluster analysis of midlatitude oceanic cloud regimes
N. D. Gordon and
J. R. Norris

\section{Title Page}

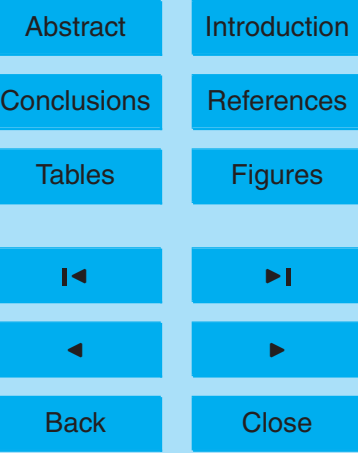

Full Screen / Esc

Printer-friendly Version

Interactive Discussion 

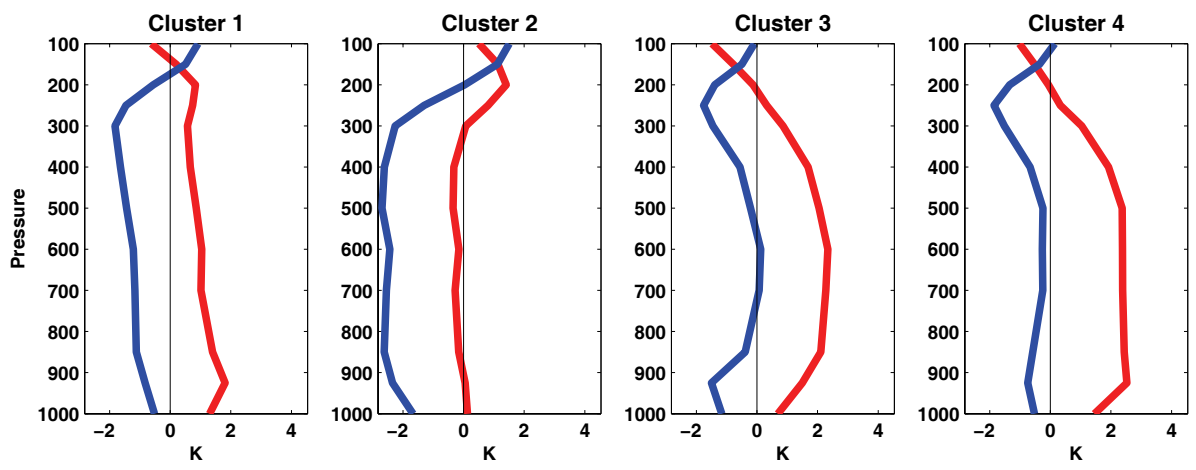

$10,1595-1629,2010$
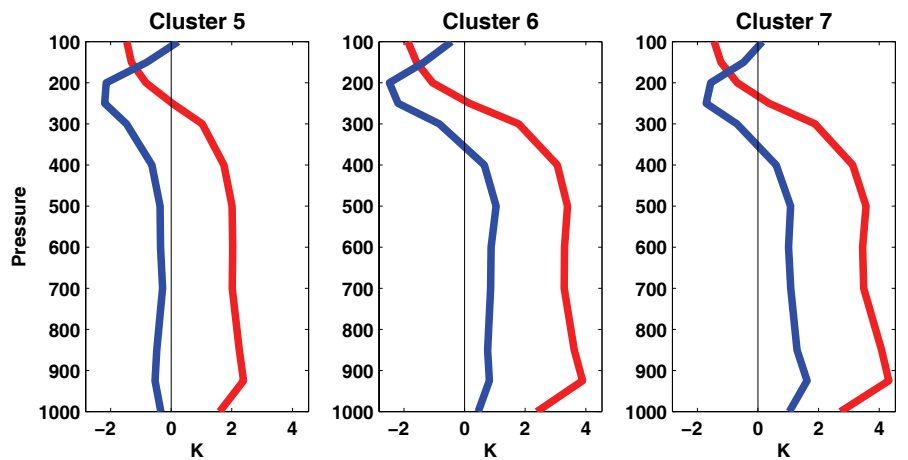

Fig. 3. Vertical profiles of temperature anomalies for warm (red) and cold (blue) subsets for each cluster from the NCEP reanalysis.

\section{Cluster analysis of} midlatitude oceanic cloud regimes
N. D. Gordon and
J. R. Norris

\section{Title Page}

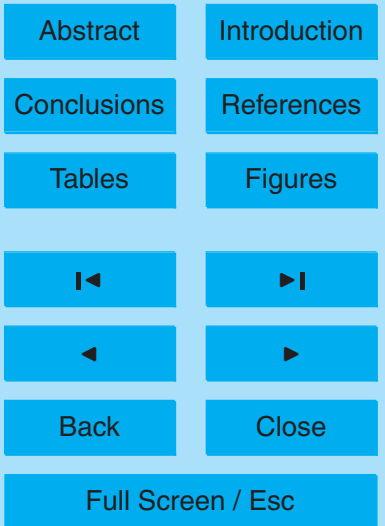

Printer-friendly Version

Interactive Discussion 


\section{ACPD}

10, 1595-1629, 2010
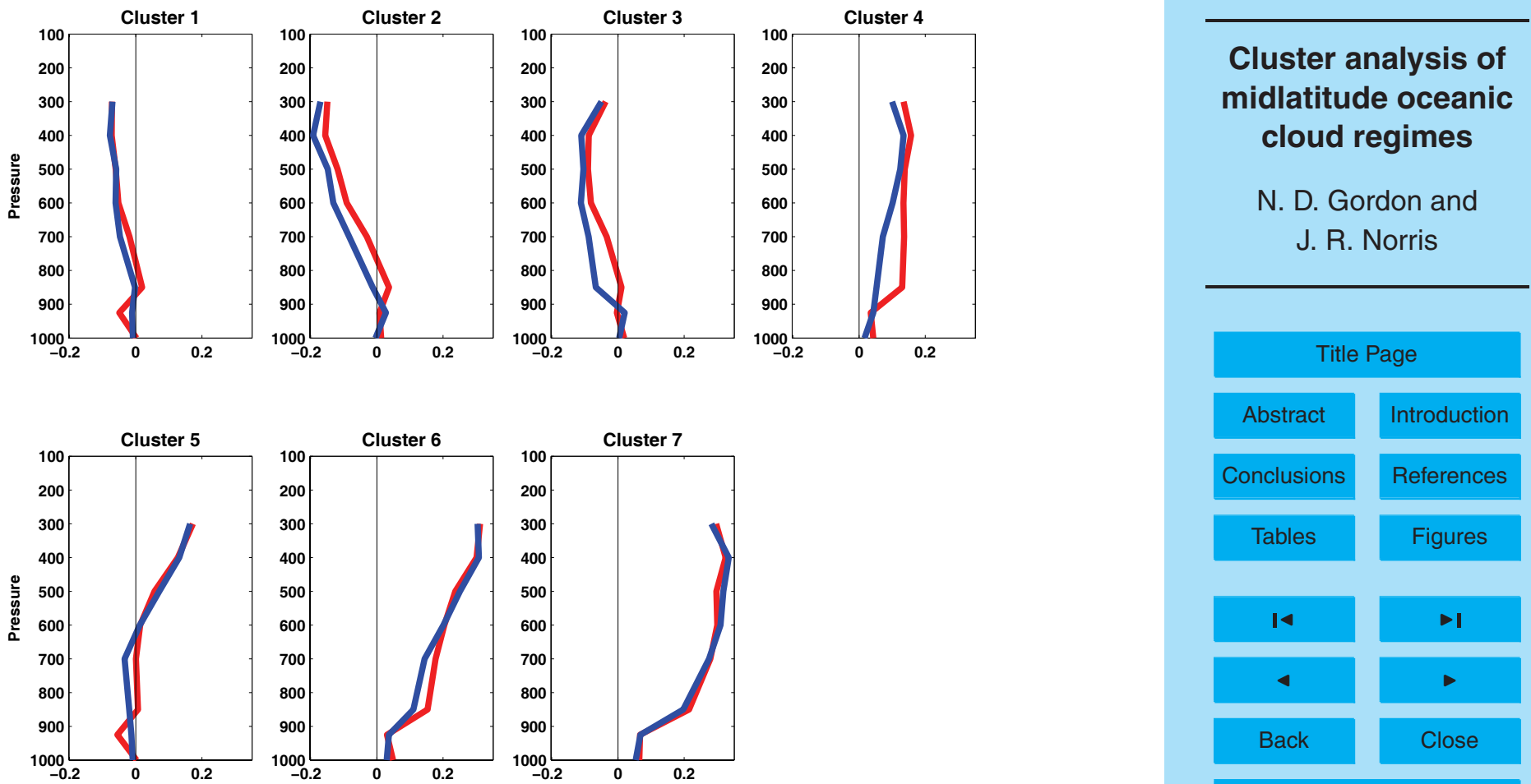

Cluster analysis of midlatitude oceanic cloud regimes
N. D. Gordon and
J. R. Norris

\section{Title Page}

Full Screen / Esc

Fig. 4. As in Fig. 3, except for relative humidity anomalies.

Printer-friendly Version

Interactive Discussion 

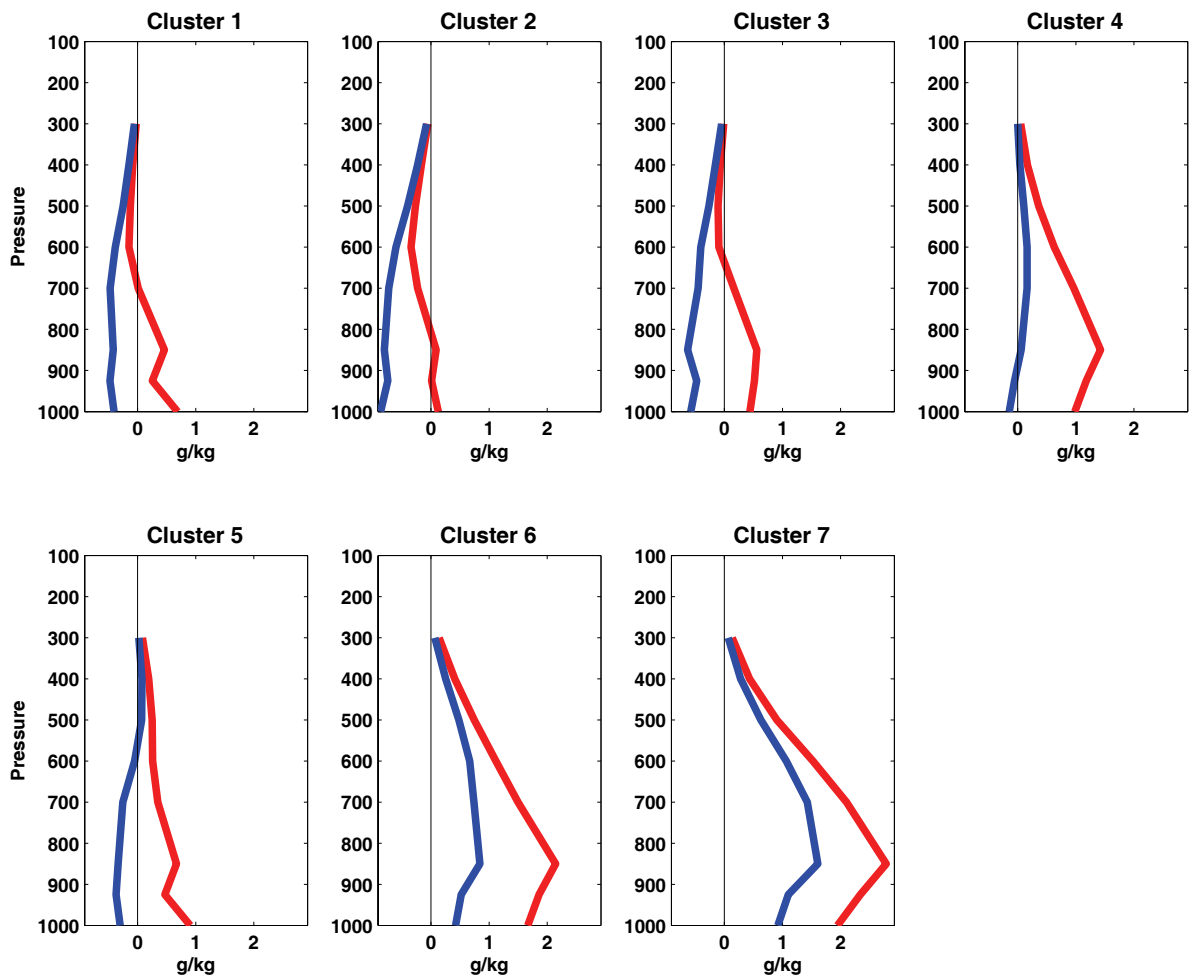

ACPD

10, 1595-1629, 2010

Cluster analysis of midlatitude oceanic cloud regimes
N. D. Gordon and
J. R. Norris

Title Page

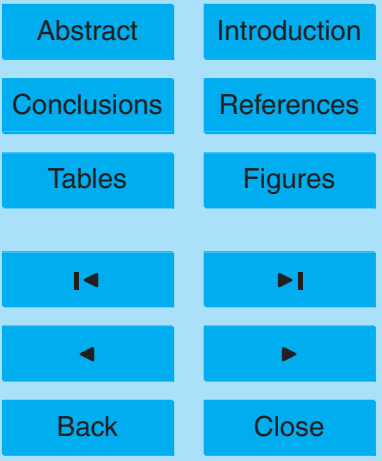

Full Screen / Esc

Fig. 5. As in Fig. 3, except for specific humidity anomalies. 

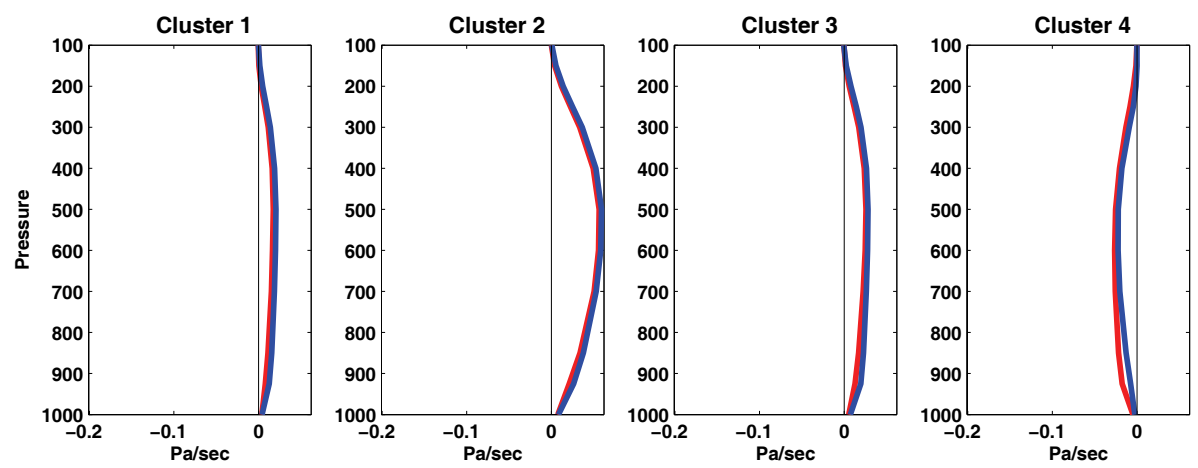

10, 1595-1629, 2010
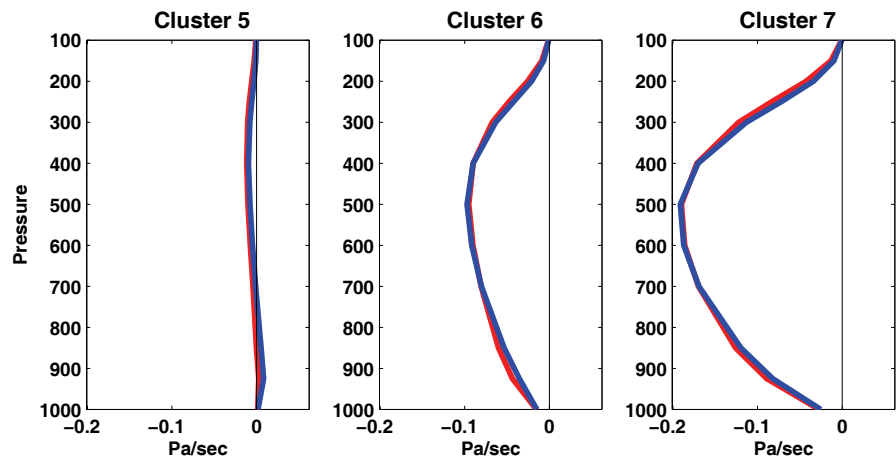

Cluster analysis of midlatitude oceanic cloud regimes
N. D. Gordon and
J. R. Norris

Title Page

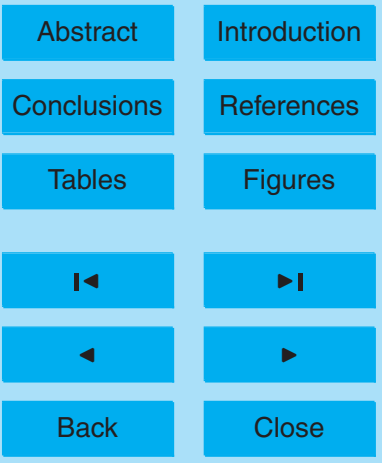

Full Screen / Esc

Fig. 6. As in Fig. 3, except for pressure vertical velocity profiles. 


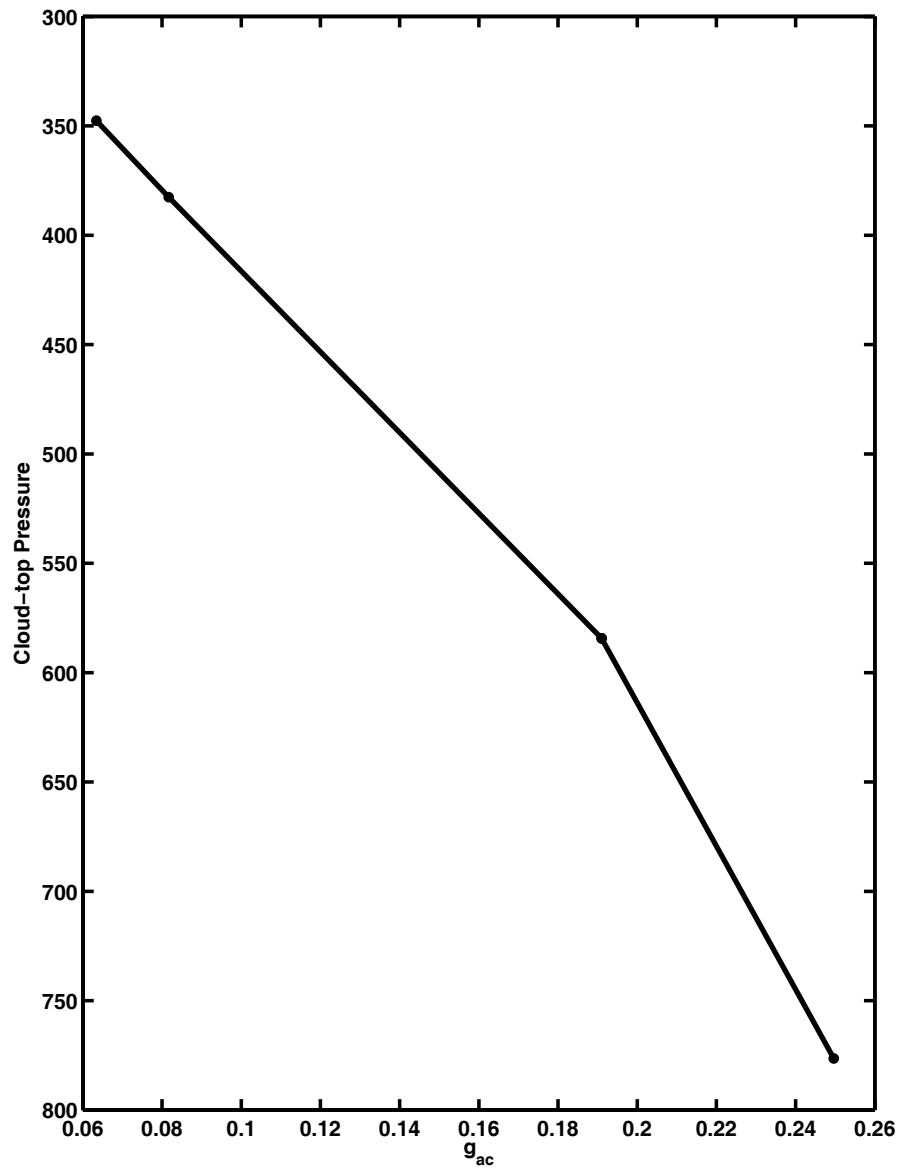

Fig. 7. Relationship between the above-cloud greenhouse parameter and cloud-top pressure.

\section{ACPD}

10, 1595-1629, 2010

Cluster analysis of midlatitude oceanic cloud regimes

N. D. Gordon and J. R. Norris

Title Page

Abstract Introduction

Conclusions References

Tables

Figures

14

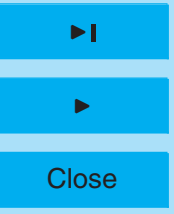

Back

Full Screen / Esc

Printer-friendly Version

Interactive Discussion 